\title{
IV. On a new electric radiation meter. (Preliminary note.)
}

\section{W. G. Gregory M.A.}

To cite this article: W. G. Gregory M.A. (1890) IV. On a new electric radiation meter. (Preliminary note.) , Philosophical Magazine Series 5, 29:176, 54-55, DOI: 10.1080/14786449008619904

To link to this article: http://dx.doi.org/10.1080/14786449008619904

央 Published online: 14 Oct 2011.

Submit your article to this journal $[\pi$

Џ Article views: 2

Q View related articles $\asymp$ 
preceding series of lunar researches was born by one of the most generous and disinterested friends that Science has had in this country, the late William Thaw, of Pittsburgh. By his own wish, no mention of his name was made in previous publications in connexion with the results so greatly indebted to his aid. His recent death seems to remove the restriction imposed by such a rare disinterestedness.

IV. On a New Electric Radiation Meter. (Preliminary Note.) By W. G. Gregori, M.A., Demonstrator in Physics at the Royal Indian Engineering College, Coopers Hill*.

THE usual method of detecting electric radiations by ob1 serving the sparking across an air-gap in ihe wire used as a receiver admits of only a rough estimate of their intensity. 'The object of this paper is to describe an instrument by means of which definite quantitative measurements may be made. It is based on the measurement of the elongation of a wire when heated by the currents induced in it by the rapidly varying field of force.

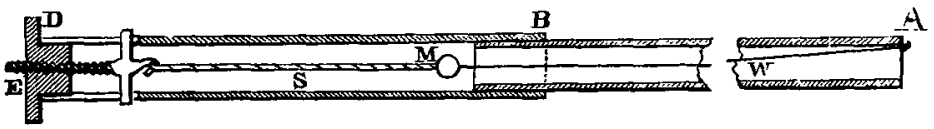

It consists of a long glass tube A B cemented to a shorter piece of brass tubing $B D$. Within is stretched a platinum wire $W$ fastened to the glass tube at $A$ and to a Perry magnifyingspring at $M$, where there is a mirror to indicate the rotation of the spring by the reflexion of a beam of light upon a scale. At $W$ there is a nut and screw for adjusting the tension. The brass tube is partially filed away in front of the mirror to form a window. The object of the brass tube is to compensate the spring for general changes of temperature, the glass tube serving the same purpose for the platinum wire.

The wire employed was $\cdot 0086 \mathrm{~cm}$. in diameter, and $192 \mathrm{cms}$. long. The spring was about $25 \mathrm{cms}$. long and $-007 \mathrm{~cm}$. in diameter. It was made out of a fine kind of tinsel $04 \mathrm{~cm}$. wide and $\cdot 0015 \mathrm{~cm}$. thick, which can be obtained ut fancy shops wound loosely on cotton. When removed from the cotton, it was already in the form of an irregular helix. It was then rolled tightly between the fingers to reduce the diameter as much as possible. A piece of silk was next attached to one end, and the spring extended almost to breaking-point, the

* Communicated by the Physical Society: read November 1, 1889. 
silk allowing it freely to untwist as much as it would. After this it was rolled between two hard surfaces and again pulled out. This was repeated till at last 10 revolutions per millimetre extension were obtained.

The mirror was a $\frac{2}{10}$-inch worked concave one, and gave a very sharp image of a wire on a scale one metre off. Using an ordinary galvanometer-scale, it was easy to read to one division. This would correspond to an elongation of the wire of 000005 of a millimetre, and a rise of temperature about - 003 of a degree Centigrade. In spite of this sensitiveness, only one or two divisions' deflexion were obtained with the oscillator 4 metres off. The oscillator used consisted of two brass rods $.53 \mathrm{~cm}$. in diameter supported horizontally and carrying two zinc plates $40 \mathrm{~cm}$. square, capable of sliding along them so that the wave-length could be altered at pleasure. They were usually kept about $25 \mathrm{~cm}$. apart. The terminal knobs were $2 \mathrm{~cm}$. in diameter and the spark-gap about 2 or 3 millim. It was noticed that one of the knobs blackened very quickly but remained quite cool, while the other, which altered little, became very hot.

The induction-coil employed to work it was $20 \mathrm{~cm}$. long and $12 \mathrm{~cm}$. diameter, and gave with the battery-power employed sparks $4 \mathrm{~cm}$. long between two points. To obtain greater regularity in the working of the coil, a tuning-fork mercury break, vibrating 86 times a second, was used.

By employing a larger coil larger deflexions could, no doubt, be obtained and effects at greater distances observed.

A method was tried for increasing the sensitiveness by weighting the mirror so that its centre of gravity was behind and rather above the axis of suspension. The tension was adjusted so that the spring kept the mirror near its position of unstable equilibrium. The effect was to render the smaller deflexions nearly 10 times as great, while the sensitiveness diminished as the deflexions became larger. But the difficulties of working with it were greatly increased, as the smallest draught of air would alter the zero-point.

Wires of different materials were also tried which should theoretically give better results ; but, probably owing to their diameters not being sufficiently fine for the tension to which they were subjected, the results were not satisfactory. The convenience of being able to compensate the platinum wire by the glass tube seems, however, a great point in favour of the use of platinum, and has led me hitherto to keep to it. 